\title{
A case of concomitant subcorneal pustular dermatosis and erythema nodosum leprosum in borderline lepromatous leprosy-relapses
}

\author{
Hendra Gunawan, Nina Roslina, Oki Suwarsa \\ Department of Dermatology and Venereology, Faculty of Medicine, Universitas Padjadjaran/Hasan Sadikin Hospital, Bandung, \\ Indonesia
}

Received: September 29, 2017

DOI: $10.5430 /$ crcp.v4n4p6
Accepted: November 8, $2017 \quad$ Online Published: November 15, 2017

URL: https://doi.org/10.5430/crcp.v4n4p6

\begin{abstract}
Subcorneal pustular dermatosis (SPD) is a rare, chronic, and recurrent pustular eruption characterized histopathologically by subcorneal pustules that contain neutrophils. SPD has been clearly reported conjunction with other diseases. Leprosy reactions are acute inflammatory process that immunologically driven on the chronic course of leprosy. Erythema nodosum leprosum (ENL) is a type II of leprosy reaction putatively can initiate SPD lesions. We report one case of concomitant SPD and ENL in borderline lepromatous leprosy-relapses. A 41-year-old man with the history of using multidrug therapy-multibacillary for leprosy presented with painful erythematous nodules on the trunk and extremities, accompanied by pustules on erythematous base on the face, arms, buttocks, and legs. There were thickening of both ulnar nerves with gloves and stocking hypesthesia. The bacterial index was $3+$ and morphological index was $20 \%$. Histopathological examination on the pustule revealed subcorneal pustules with exocytosis of neutrophils which supported the diagnosis of SPD. A possible immunologic mechanism has been suggested in the induction of the occurence both SPD and ENL.
\end{abstract}

Key Words: Subcorneal pustular dermatosis, Erythema nodosum leprosum

\section{INTRODUCTION}

Subcorneal pustular dermatosis (SPD) is a rare and recurrent skin disorder characterized by vesicles or pustules that break easily on the base of normal or erythematous skin. The histopathological hallmark of the disease is subcorneal pustules filled with polymorphonuclear leukocytes. ${ }^{[1]}$ SPD sometimes arises in conjunction with other diseases such as pyoderma gangrenosum, ${ }^{[2]}$ systemic lupus erythematosus (SLE), ${ }^{[3]}$ and rheumatoid arthritis. ${ }^{[4]}$ To the authors' knowledge only two cases about concomitant SPD and leprosy. ${ }^{[5]}$ Leprosy reaction is an acute inflammatory episode caused by an immune response to Mycobacterium leprae (M. leprae) on the course of chronic leprosy. Two types of leprosy reaction are type I and type II. Type II leprosy reaction also referred erythema nodosum leprosum (ENL) is an immunologic reaction characterized by immune complex deposits in many tissues and organs. ${ }^{[6]}$ This condition may a trigger to develop SPD. ${ }^{[5]}$ Here, we reported one case of concomitant SPD and ENL in borderline lepromatous (BL) leprosy-relapses.

\section{CaSe presentation}

A 41-year-old Indonesian man was diagnosed as leprosy in June 2010 and released from 12 months treatment with multidrug therapy-multibacillary (MDT-MB). In 2016, the

\footnotetext{
*Correspondence: Hendra Gunawan; Email: endaguna@yahoo.com; Address: Department of Dermatology and Venereology, Faculty of Medicine, Universitas Padjadjaran/Hasan Sadikin Hospital, Pasteur street no.38, Bandung, 40160, Indonesia.
} 
patient was hospitalized in Department of Internal Medicine due to fever, arthralgia, Cushingoid habitus, and painful erythematous nodules on the face, trunk, and extremities. The patient then referred to Department of Dermatology. There was a history of long-term oral corticosteroids used. Physical examination showed moon face, central obesity, claw hands, and atrophy of thenar and hypothenar muscles. Multiple erythematous nodules and hyperpigmented macules were found on the face, trunk, and extremities (see Figure 1A). There was also multiple hypopigmented macules on the face. Both ulnar nerves were thickened with gloves and stocking hypesthesia. Bacterial index (BI) was 3+ and morphological index (MI) was 20\%. The patient was diagnosed as BL leprosy-relapses and received MDT-MB and prednisone 40 $\mathrm{mg} /$ day. Ten days later, appeared itchy fragile pustules on an erythematous base on the face (see Figure 1B,C), arms, legs (see Figure 1D) and buttocks with annular pattern. Blood test revealed leukocytosis $\left(26,000 / \mathrm{mm}^{3}\right)$, normal serum cortisol levels $(12.96 \mu \mathrm{g} / \mathrm{dl})$, and increased immunoglobulin (Ig) M anti-phenolic glycolipid-I (PGL-I) (IgM 1,214 u/ml). The Gram staining taken from the pustules and its culture were sterile. Histopathological examination of an intact pustule lesion from buttocks showed mild focal acanthosis on the epidermal layer with spongiosis, and subcorneal pustules with exocytosis of neutrophils. Mild infiltration of inflammatory cells was found on the papilla dermis (see Figure 2A-B) which supported the diagnosis of SPD. Dapsone is the drug of choice for SPD and the patient has received MDT-MB regimen, a combination of rifampicin, clofazimine, and dapsone. The improvement of pustular lesions and ENL was seen on the day 24 of observations period. Unfortunately, there has been a recurrence of pustular lesions and ENL in this patient.
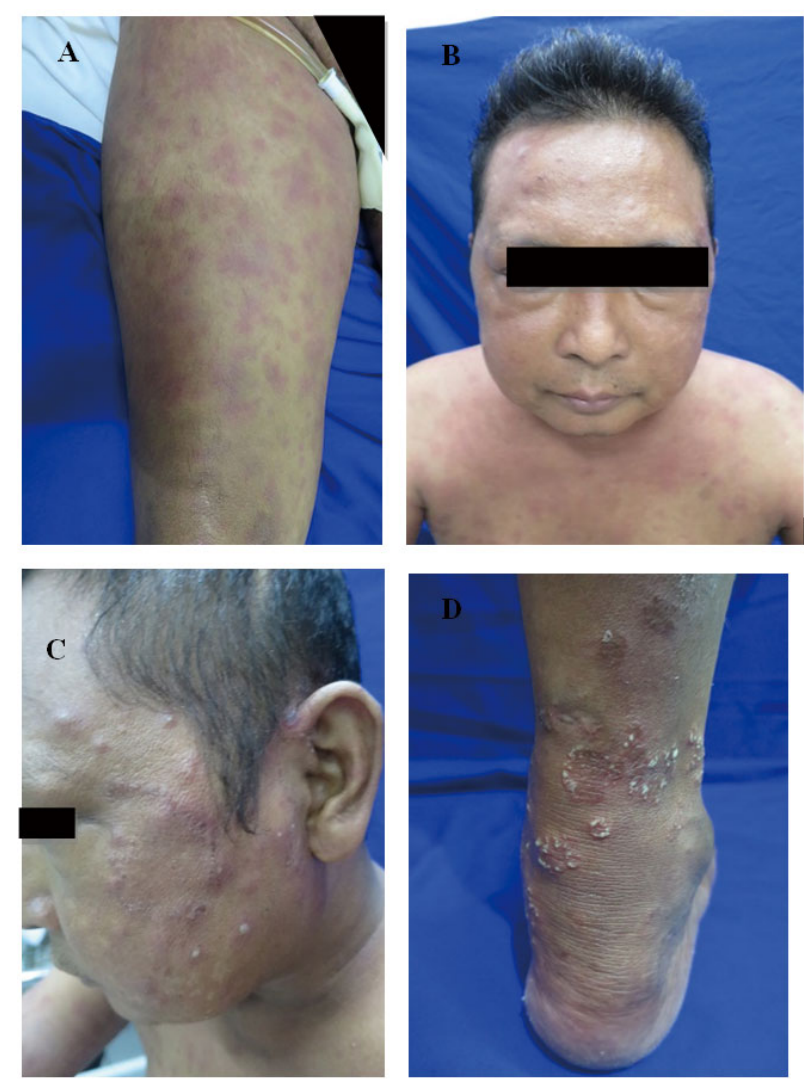

Figure 1. Clinical finding. (A-B) Erythematous nodules. (C) Fragile pustules on erythematous base. (D) The pustular lesions are arranged in annular pattern.
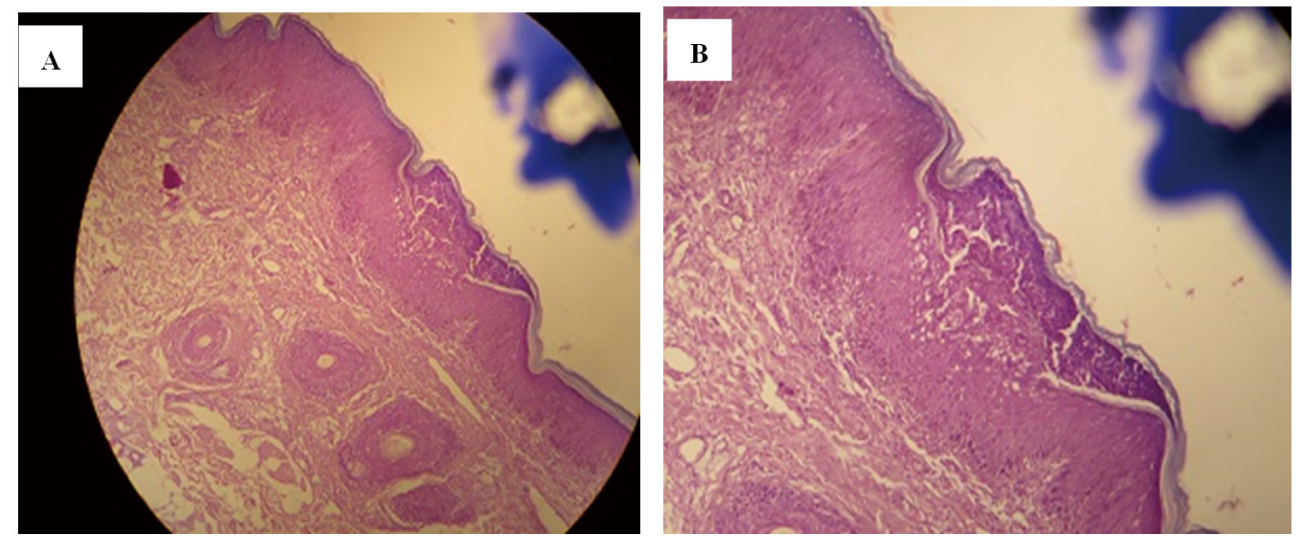

Figure 2. Histopathological finding. (A) Lower-power imaging of the pustular lesion revealed subcorneal pustule (hematoxylin and eosin, $\times 12.5$ ). (B) Mild focal acanthosis on the epidermal layer with spongiosis, and subcorneal pustules with exocytosis of neutrophils. Papilla dermis showed mild infiltration of inflammatory cells.

\section{Discussion}

Subcorneal pustular dermatosis was described by Sneddon and Wilkinson in 1956. ${ }^{[1]}$ The clinical characteristic of SPD

Published by Sciedu Press is an accumulation of pus in the lower half of the pustules, leaving clear fluid in the upper half. ${ }^{[7]}$ The pustules is flaccid and tends to coalesce to form an annular, circinar, or ser- 
piginous pattern. ${ }^{[7,8]}$ The eruptions affect mainly in flexure, groin, abdomen, and flexor aspect of the limbs. ${ }^{[1,7]}$

The etiology of SPD is unknown. ${ }^{[1,9]}$ There are several mechanisms that can trigger SPD such as immunological mechanisms and the presence of infection that precedes or concomitant with SPD. ${ }^{[1]}$ Pavithran ${ }^{[5]}$ reported a case of concomitant SPD with type II leprosy reaction in lepromatous leprosy patient. It suggested that autoimmune mechanisms play a role in the induction of ENL. Deposition of immune complexes and the infiltration of polymorphonuclear cells release of tumor necrosis factor- $\alpha$ (TNF- $\alpha$ ) during ENL. ${ }^{10]}$ Sarno et al. ${ }^{[11]}$ reported the elevation of TNF- $\alpha$ serum level in ENL patients. The elevation of TNF- $\alpha$ concentration in the serum and blister fluid were also observed in patients with SPD. ${ }^{[12]}$ TNF- $\alpha$ is a chemotactic factor for neutrophils to migrate into upper epidermis and forming subcorneal pustules. ${ }^{[8]}$ Increased production of TNF- $\alpha$ is suspected to cause neutrophils hyperactivation. ${ }^{[1,12]}$ In addition, TNF- $\alpha$ can drive the upregulation of transcription factor mainly nuclear factor $-\kappa \mathrm{B}(\mathrm{NF}-\kappa \mathrm{B})$ signaling pathways. ${ }^{[14]}$ The expression of NF- $\kappa$ B can induce inflammation through accelerate neutrophils stimulation. ${ }^{[15]}$ TNF- $\alpha$ has been identified as a crtitical mediator of inflammation in several autoimmune diseases including cutaneus vasculitis, SLE and psoriasis. ${ }^{[16]}$

Histopathological features of SPD is characterized by subcorneal pustules containing neutrophils. ${ }^{[1,7]}$ Other features that may be found on SPD include some acantholytic cells in older pustular lesions (secondary acantholysis) due to proteolytic enzyme activity released by neutrophils. Mitotic figures are usually absent. There are perivascular infiltrate in the dermis contain neutrophils and rarely mononuclear cells and eosinophils. ${ }^{[13]}$

In our patient, SPD lesions appear almost simultaneously with ENL lesions. This case could explained that the development and progression of SPD lesions are present due to autoimmunity that triggered by ENL. Furthermore, therapy of dapsone for SPD and prednisone for ENL are aimed to inhibit the migration of neutrophils because both of them have the same immunological mechanisms. ${ }^{[1,2,17]}$ Anti-TNF- $\alpha$ treatment, such as infliximab, ${ }^{[18]}$ etanercept, ${ }^{[19]}$ and adalimumab $^{[20]}$ for recalcitrant SPD has given good responses. The impressive clinical response was also obtained after treatment of etanercept ${ }^{[21-23]}$ and infliximab, ${ }^{[24]}$ in ENL patients. Therefore, anti-TNF- $\alpha$ may be considered as an alternative therapy for both SPD and ENL that has not responded to standard therapies.

This case report highlights a rarely of concomitant SPD and ENL case. Assuming that the autoimmunity highly contributes to SPD lesions triggered by ENL. Additionally, the uncontrolled of ENL case in leprosy patient could increase the TNF- $\alpha$ level, therefore lead to develop SPD.

\section{CONFlicts OF InTEREST Disclosure}

The authors declare that there is no conflict of interest.

\section{REFERENCES}

[1] Trautinger F, Honigsmann H. Subcorneal pustular dermatosis. Dalam: Goldsmith LA, Katz SI, Gilchrest BA, Paller AS, Leffell DJ, Wolff K, editors. Fitzpatrick's dermatology in general medicine. 8th editions. New York: McGraw-Hill; 2012. 383-3855p.

[2] Ahmad K, Ramsay B. Pyoderma gangrenosum associated with subcorneal pustular dermatosis and IgA myeloma. Clin Exp Dermatol. 2008; 34: 46-48. PMid:18627386. http://dx.doi.org/10.1111 /j.1365-2230.2008.02886

[3] Saulsbury FT, Kesler RW. Subcorneal pustular dermatosis and systemic lupus erythematosus. Int J Dermatol. 1984; 23: 63-64. http://dx.doi.org/10.1111/j.1365-4362.1984.tb05666

[4] Roger H, Thevener JP, Souteyrand P, et al. Subcorneal pustular dermatosis associated with rheumatoid arthritis and raised $\operatorname{IgA}$ : simultaneous remission of skin and joint involvements with dapsone treatment. Ann Rheum Dis. 1990; 49: 190-191. PMid:2181947. http://dx.doi.org/10.1136/ard.49.3.190

[5] Pavithran K. Subcorneal pustular dermatosis in type 2 lepra reaction. Int J Lepr Other Mycobact Dis. 1992; 60(1): 89-91. ISSN 0148-916X.

[6] Moschella SL. An update on the diagnosis and treatment of leprosy. J Am Acad Dermatol. 2004; 51: 417-426. PMid:15337986. https://doi.org/10.1016/j.jaad.2003.11.072
[7] Wojnarowska F, Venning VA. Subconeal pustular dermatosis. In: Burns T, Breathnach S, Cox N, Griffiths C, editors. Rook's text book of dermatology. 8th editions. UK: Wiley-Blackwell; 2010. 40. 21-22 p.

[8] Cheng S, Edmonds E, Ben-Gashir M, et al. Subcorneal pustular dermatosis: 50 years on. Clin Exp Dermatol. 2008; 33: 229-233. PMid:18355359. http://dx.doi.org/10.1111/j.1365-2230. 2008.02706

[9] Kachemoune A, Blyumin ML. Sneddon-Wilkinson disease resistant to dapsone and colchicine successfully controlled with PUVA. Dermatol Online J [Internet]. 2003 May [cited 2015 May 10]; 9(5): 24-27. Available from: http://escholarship.org/uc/item/1 vn304vn

[10] Kahawita IP, Lockwood DNJ. Towards understanding the pathology of erythema nodosum leprosum. Trans R Soc Trop Med Hyg. 2008; 102: 329-337. PMid:18313706. http://dx.doi.org/10.1016/j .trstmh.2008.01.004

[11] Sarno EN, Vieira LMM, Nery JA. Serum levels of tumor necrosis factor- $\alpha$ and interleukin- $\beta$ during leprosy reactional states. Clin Exp Immunol. 1991; 84: 103-108. PMid:2015700.

[12] Grob JJ, Mege JL, Capo C, et al. Role of tumor necrosis factor- $\alpha$ in Sneddon-Wilkinson subcorneal pustular dermatosis. A model of 
neutrophil priming in vivo. J Am Acad Dermatol. 1991; 25: 944-947. https://doi.org/10.1016/0190-9622(91)70290-I

[13] Weedon B. Tissue reaction patterns. In: Weedon B, editor. Skin pathology. 3rd editions. British: Elsevier; 2010. 129-130 p.

[14] Levine SJ. Tumor necrosis factor alpha (TNF- $\alpha$ ) [Internet]. USA: National Institutes of Health; c2015 [cited 2017 Nov 3]. Available from: www.ssnpstudents.com/wp/wp-content/uploads/201 5/02/00368.pdf

[15] McDonald PP, Bald A, Cassatella MA. Activation of the NF- $\kappa$ B pathway by inflammatory stimuli in human neutrophils. Blood [Internet]. 1997 May [cited 2017 November 3]; 9(88): 3241-3433. Available from: http://www.bloodjournal.org/content/89/9/342

[16] Voigtlander C, Luftl M, Schuler G, et al. Infliximab (anti-tumor necrosis factor $\alpha$ antibody. Arch Dermatol. 2001; 137(12): 15711574. PMid:11735706. http://www.doi.org/10.1001/archde rm.137.12.1571

[17] Sago JG, Hall RP. Dapsone. In: Goldsmith LA, Katz SI, Gilchrest BA, Paller AS, Leffell DJ, Wolff K, editors. Fitzpatrick's dermatology in general medicine. 8th editions. New York: McGraw-Hill; 2012. 2721-2726 p.

[18] Kretschmer L, Maul JT, Hofer T, et al. Interruption of SneddonWilkinson subcorneal pustulation with infliximab. Case Rep Dermatol. 2017; 9: 140-144. PMid:28559813. http://www.doi.org/10 $.1159 / 000468917$
[19] Berk DR, Hurt MA, Mann C, et al. Sneddon-Wilkinson disease treated with etanercept: report of two cases. Clin Exp Dermatol 2008; 34: 347-351. PMid:18699836. http://dx.doi .org/10.11 $11 / j .1365-2230.2008 .02905$

[20] Howell SM, Bessinger GT, Altman CE, et al. Rapid response of IgA pemphigus of the subcorneal pustular dermatosis subtype to treatment with adalimumab and mycophenolate mofetil. J Am Acad Dermatol. 2005; 53(3); 541-543. PMid:16112379. http://dx.doi . org $/ 10.1016 / j$. jaad . 2005.02.051

[21] Ramien ML, Wong A, Keystone JS. Severe refactory erythema nodosum leprosum successfully treated with the tumor necrosis factor inhibitor etanercept. Clin Infect Dis. PMid:21292656. 2011; 52(5): 133-135. https://doi.org/10.1093/cid/ciq213

[22] Santos JRS, Vendramini DL, da Costa Nery JA, et al. Etanercept in erythema nodosum leprosum. An Bras Dermatol. 2017; 92(4): 575-577. PMid:28954119. http://dx.doi.org/10.1590/abd18 06-4841.20175471

[23] Thangaraju P, Durai V, Showkath Ali MK. The role of etanercept in refractory erythema nodosum leprosum. Int J Mycobacteriol. 2016; 5: 368-369. PMid:27847029. http://dx.doi.org/10.1016/j.i jmyco.2016.07.002

[24] Faber WR, Jensema AJ, Goldschmidt WFM. Treatment of recurrent erythema nodosum leprosum with inflixi3mab. N Eng J Med. 2006; 355: 739. PMid:16914716. http://dx.doi.org/10.1056/NEJ Mc052955 